\title{
Evaluation of the in vitro expression of ATP binding-cassette $(A B C)$ proteins in an Ixodes ricinus cell line exposed to ivermectin
}

\author{
Carlo Mangia ${ }^{1}$, Alice Vismarra ${ }^{1}$, Laura Kramer ${ }^{1 *}$, Lesley Bell-Sakyi ${ }^{2}$, Daniele Porretta ${ }^{3}$, Domenico Otranto ${ }^{4}$,
} Sara Epis ${ }^{5}$ and Giulio Grandi ${ }^{6}$

\begin{abstract}
Background: Ticks are among the most important vectors of pathogens causing human and animal disease. Acaricides are used to control tick infestation, although there are increasing reports of resistance. Recently, overexpression of ATP-binding cassette (ABC) transporter proteins (P-glycoproteins, PgP) has been implicated in resistance to the acaricide ivermectin in the ticks Rhipicephalus (Boophilus) microplus and Rhipicephalus sanguineus sensu lato. Ixodid tick cell lines have been used to investigate drug resistance mechanisms. The aim of the present study was to evaluate expression of several PgPs in the Ixodes ricinus-derived cell line IRE/CTVM19 and to determine modulation of expression following treatment with ivermectin.

Findings: IRE/CTVM19 cells were treated with different concentrations of ivermectin $(0,11,22$ or $33 \mu \mathrm{M})$ and incubated for 10 days. Evaluation of viability and relative expression of $A B C B 1, A B C B 6, A B C B 8$ and $A B C B 10$ genes were carried out at day 10 post treatment. Cell viability ranged between $84 \%$ and $92 \%$ with no significant differences between untreated and treated cells. QRT-PCR showed that ABC pump expression was not significantly modulated by ivermectin treatment. Expression of the ABCB8 PgP subfamily revealed a biphasic trend, based on the ivermectin concentration. $\mathrm{ABCB} 6$ and $\mathrm{ABCB} 10$ gene expression was not modulated by ivermectin treatment and $A B C B 1$ expression was not detected.
\end{abstract}

Conclusions: This is the first report of PgP expression in an I. ricinus-derived tick cell line. Development of an in vitro model for the study of acaricide resistance mechanisms would greatly facilitate screening for drug resistance in ticks.

Keywords: ATP-binding cassette transporter, Ixodes ricinus, Tick cell line, in vitro, Ivermectin

\section{Findings}

\section{Background}

Ticks are among the most important vectors of a wide range of pathogens causing human and animal diseases, and several classes of acaricide are widely used to control tick infestation $[1,2]$. However, there is an increasing number of reports of resistance to acaricides including macrocyclic lactones [3]. One of the most widely studied mechanisms of drug resistance is associated with the protein family of $A B C$ transporters, which transport toxic substances outside the cell, thereby

\footnotetext{
* Correspondence: kramerlh@unipr.it

'Department of Veterinary Sciences, University of Parma, 43126 Parma, Italy

Full list of author information is available at the end of the article
}

reducing their concentration inside the cell [4]. These efflux pumps are able to eliminate both endogenous and exogenous toxins and are an important "first-line" defence mechanism. Recent studies have shown that $A B C$ transporters are present in a wide range of organisms, including mammals and arthropods, and have been implicated in drug resistance in ticks [5-7]. A recent study reported that over-expression of a gene encoding for $\mathrm{ABC}$-multidrug transporters was associated with in vitro-induced resistance to ivermectin in the tick cell line BME26 [8], derived from embryos of the cattle tick Rhipicephalus (Boophilus) microplus [9]. In addition, $\mathrm{ABC}$ transporters may be involved in detoxification in the brown dog tick Rhipicephalus sanguineus (sensu lato) 
[10]. Despite increasing evidence that $A B C$ transporters are likely to be involved in acaricide resistance in ticks, there have been no studies in Ixodes ricinus, one of the most important vectors of pathogens causing tick-borne diseases in Europe. Ixodid tick cell lines have already been used as a model for the study of drug resistance [8, 11]. The development of an in vitro model for the study of molecular resistance mechanisms and the screening of potential genetic markers of resistance in I. ricinus would be of great scientific interest.

The aim of the present study was to evaluate the expression of selected members of the $A B C$ transporters subfamily B (ABCB1, ABCB6, ABCB8 and ABCB10) in vitro, following ivermectin treatment of the I. ricinus cell line IRE/CTVM19. Ivermectin was chosen as the test acaricide both because of its use in previous published studies on $\mathrm{ABC}$ transporters $[6-8,10]$ and because it has been shown to be active against $I$. ricinus ticks [12].

\section{Methods \\ Reagents}

All reagents were purchased from Sigma Aldrich (Milan, Italy) except where indicated.

\section{Cell line maintenance}

Cells of the I. ricinus embryo-derived cell line IRE/ CTVM19 [13] were seeded in flat sided $10 \mathrm{ml}$ tubes (Nunc) in Leibovitz's L-15 medium (Life Technologies, Milan, Italy) supplemented with $20 \%$ fetal bovine serum, $10 \%$ tryptose phosphate broth, $2 \mathrm{mM}$ L-glutamine, penicillin $(100 \mathrm{U} / \mathrm{ml})$ and streptomycin $(100 \mu \mathrm{g} / \mathrm{ml})$ and incubated at $28{ }^{\circ} \mathrm{C}$. Medium (3/4 volume) was replaced weekly and cells were split at intervals of at least 15 days.

\section{Treatment of IRE/CTVM19 cells with ivermectin}

IRE/CTVM19 cells seeded at a concentration of $3 \times 10^{6}$ cells $/ \mathrm{ml}$ in $2 \mathrm{ml}$ culture medium per tube were treated immediately with different concentrations of ivermectin in $0.1 \%$ DMSO $(11 \mu \mathrm{M}, 22 \mu \mathrm{M}$ or $33 \mu \mathrm{M})$. Untreated cells and cells treated with $0.1 \%$ DMSO only served as controls. Cultures were incubated for 10 days and medium was changed on the seventh day. Replacement media contained the same concentrations of ivermectin as reported above.

\section{Growth curve and cell viability}

For growth rate analysis, four replicate tubes were used per treatment. On days 0,5 and 10, a small aliquot of cell suspension was harvested from each tube, labelled with Trypan Blue $0.4 \% \mathrm{w} / \mathrm{v}$ and counted using a haemocytometer. A test of cell viability was also performed on day 5 of treatment using the LIVE/DEAD Fixable NearIR stain kit (Life Technologies). Cells were stained according to the manufacturer's instructions and analysed by flow cytometry. Flow cytometry was performed using a BD FACSVerse (BD Biosciences, Stockholm, Sweden) equipped with $488 \mathrm{~nm}$ blue and $633 \mathrm{~nm}$ red lasers, and results were analysed using the FACSDiva (BD Biosciences) software. Cells frozen at $-80{ }^{\circ} \mathrm{C}$ and thawed three times were used as negative controls.

\section{RNA extraction and determination of gene expression profile after acaricide treatment}

On day 10 following the start of ivermectin treatment, RNA was extracted from samples of resuspended cells from each replicate culture using an RNeasy Mini Kit (Qiagen) following the manufacturer's instructions. RNA was measured by spectrophotometric analysis for quality and content and then converted into cDNA using a QuantiTect Reverse Transcription Kit (Qiagen). The resultant cDNAs were used as templates for molecular analysis. To date, there is no published information about $I$. ricinus sequences for any of the pumps under investigation (those encoded by the ABCB1, ABCB6, $\mathrm{ABCB} 8$ and $\mathrm{ABCB} 10$ genes); thus primers were designed (Table 1) based on conserved regions of sequences of selected $\mathrm{ABC}$ transporters of $I$. scapularis available in VectorBase (ABCB1: ISCW004310; ABCB6: ISCW021257; ABCB8: ISCW005908; ABCB10: ISCW008199) [14]. As an endogenous control, the $I$. ricinus $\beta$-actin gene was chosen and primers were designed based on the partial sequence available in Genbank (HQ682101). Primers were first tested in a traditional PCR using cDNA derived from an untreated control IRE/CTVM19 culture and reactions were run on a $2 \%$ agarose gel stained with SYBR Safe Gel and examined under UV light (UView mini Transilluminator, Biorad) (Fig. 1). The amplification fragments, obtained using standard PCR conditions and the thermal profile indicated below, were sequenced in order to confirm the specificity of the amplification.

Table 1 Primers used in the present study for evaluation of expression of the $A B C$ subfamily $B$ genes ( $A B C B 1, A B C B 6, A B C B 8$ and $A B C B 10)$ in the Ixodes ricinus cell line IRE/CTVM19

\begin{tabular}{lllll}
\hline \multicolumn{5}{c}{ Primer sequences } \\
\hline ABCB1 & F: & $5^{\prime}-$ & TCTITGCCGTCTTCTACAG & $-3^{\prime}$ \\
& R: & $5^{\prime}-$ & CAGGTTCTCTCCAGCGAT & $-3^{\prime}$ \\
ABCB6 & F: & $5^{\prime}-$ & AGACTATGTCCTCTTCCTCA & $-3^{\prime}$ \\
& R: & $5^{\prime}-$ & CATCTATCACCTCTGCCTT & $-3^{\prime}$ \\
ABCB8 & F: & $5^{\prime}-$ & ATCAGGAACGCCGACATC & $-3^{\prime}$ \\
& R: & $5^{\prime}-$ & AGTTCCAGTAGACACCCTT & $-3^{\prime}$ \\
ABCB10 & F: & $5^{\prime}-$ & TGTCCTAACCATTGCTCACA & $-3^{\prime}$ \\
& R: & $5^{\prime}-$ & TGATGTTCCACTAATGTCCG & $-3^{\prime}$ \\
B-Actin & F: & $5^{\prime}-$ & CACGGCATCGTGACCAACTG & $-3^{\prime}$ \\
& R: & $5^{\prime}-$ & CGAACATGATCTGAGTCATCTTCTC & $-3^{\prime}$ \\
& & & &
\end{tabular}




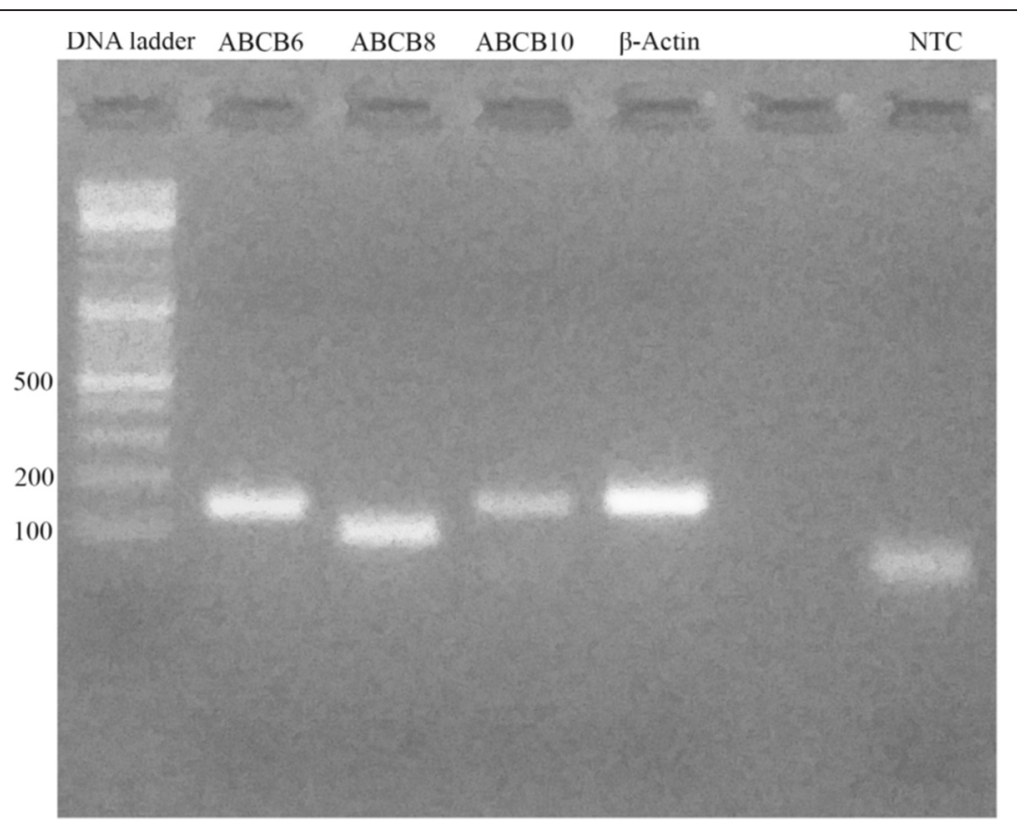

Fig. 1 Primer couples tested in traditional PCR. All fragments were approximately 101-157 bp long. The no-template control (NTC) presented a spot due to primer dimerization

The resultant sequences were deposited in the EMBL Nucleotide Sequence Database (ABCB6: LT222036; ABCB8: LT222037; ABCB10: LT222038).

$\mathrm{ABC}-\mathrm{B}$ subfamily protein expression was then evaluated by quantitative RT-PCR, using the SYBR Green master mix kit (EuroClone), according to the manufacturer's instructions. The final concentration of each primer in all the reactions was $0.4 \mu \mathrm{M}$. The amplification protocol was characterised by a denaturation step $\left(95^{\circ} \mathrm{C}\right.$ for $2 \mathrm{~min}$ ) and 45 repeated cycles $\left(95{ }^{\circ} \mathrm{C}\right.$ for $10 \mathrm{~s} ; 56^{\circ} \mathrm{C}$ for $15 \mathrm{~s} ; 72{ }^{\circ} \mathrm{C}$ for $20 \mathrm{~s}$ ). Fluorescence signals were collected in every cycle and the presence of nonspecific products was excluded through analysis of the melting curves. Results were presented as the mean \pm S.E.M. of three experiments with four replicates each, managed by CFX Manager software (Biorad) and expressed as Relative Normalised Expression $(\Delta \Delta \mathrm{Cq})$.

\section{Data analysis}

One-way ANOVA with Dunnett's post-hoc test was performed using GraphPad Prism version 6(GraphPad
Software, San Diego California USA, www.graphpad.com). $P$-values $<0.05$ were considered statistically significant.

\section{Results and discussion}

Growth curve analysis revealed a doubling-time of approximately ten days for IRE/CTVM19 cells under all conditions. IVM treatment modified cell morphology and adherance to the plastic tube, but did not alter cell viability (Fig. 2). As measured by Trypan Blue exclusion assay (data not shown) and flow-cytometry (Fig. 3), viability was $92 \%$ in the untreated control cells and between $84 \%$ and $88 \%$ in cells treated with DMSO alone or with IVM. Differences between groups were not significant.

Quantitative RT-PCR analysis showed that $A B C$ gene expression was present in IRE/CTVM19 cells but not significantly modulated following ivermectin treatment (Fig. 4). Expression of the ABCB1 gene was not detectable at any time point in any condition (data not shown). $\mathrm{ABCB} 6, \mathrm{ABCB} 8$ and $\mathrm{ABCB} 10$ were detected, but no significant differences were seen between untreated and treated cultures or between different doses of IVM.
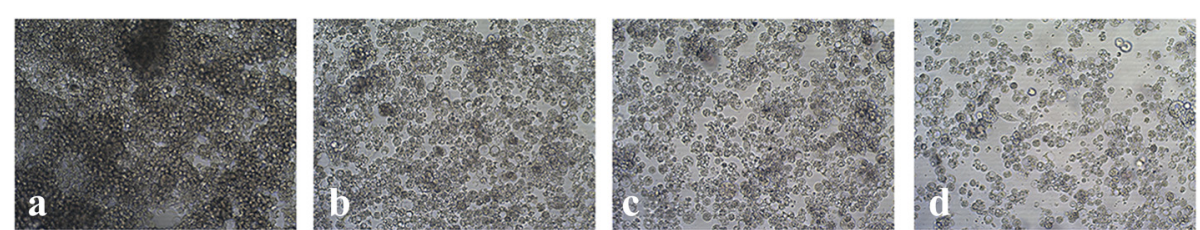

Fig. 2 Morphology and density of IRE/CTVM19 cell line following IVM treatment. Increasing concentration of IVM (b: $11 \mu M$; c: $22 \mu M$; d: $33 \mu M)$ determined larger and more vacuolated cells compared to untreated control (a). Pictures were captured at $100 \times$ magnification 


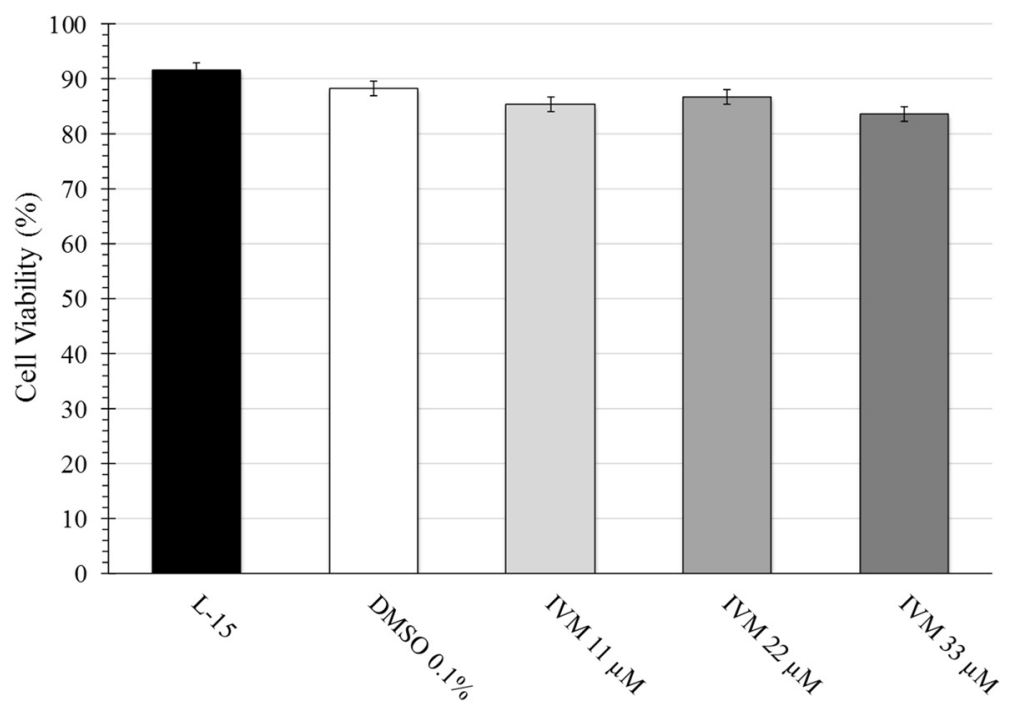

Fig. 3 IRE/CTVM19 cell viability on day 5 of cultivation either untreated (L-15), treated with 0.1\% DMSO alone (DMSO $0.1 \%$ ) or treated with ivermectin (IVM) in $0.1 \%$ DMSO at concentrations of 11, 22 or $33 \mu \mathrm{M}$. Cells were evaluated by flow cytometry following Live vs. Dead ${ }^{\otimes}$ staining and data represents the mean of four replicate tubes \pm S.E.M. Viability measured by Trypan Blue exclusion on days 5 and 10 was comparable (data not shown)

To the authors' knowledge, this is the first report of expression and modulation of $\mathrm{ABC}$ transporters in an $I$. ricinus-derived cell line. The relative expression of $\mathrm{ABC}$ genes in ivermectin-treated cells ranged between 0.5 and 1.6 fold compared to the time zero control. Interestingly, ABCB8 expression showed a particular, biphasic doseresponse relationship, with a low-dose stimulation and a high-dose return to the control level, as reported by Calabrese for drug-resistant vertebrate cell lines [15].
The results presented here indicate the need for further study.

Furthermore, ivermectin has been incriminated as an inhibitor of detoxification mechanisms in mammalian cell lines [16] and the results regarding $A B C B 8$ in the present study suggest that the inhibitor effect may also be true for I. ricinus tick cell lines. In the only other similar in vitro study published so far [8], a clear role for ivermectin could be demonstrated both in terms of

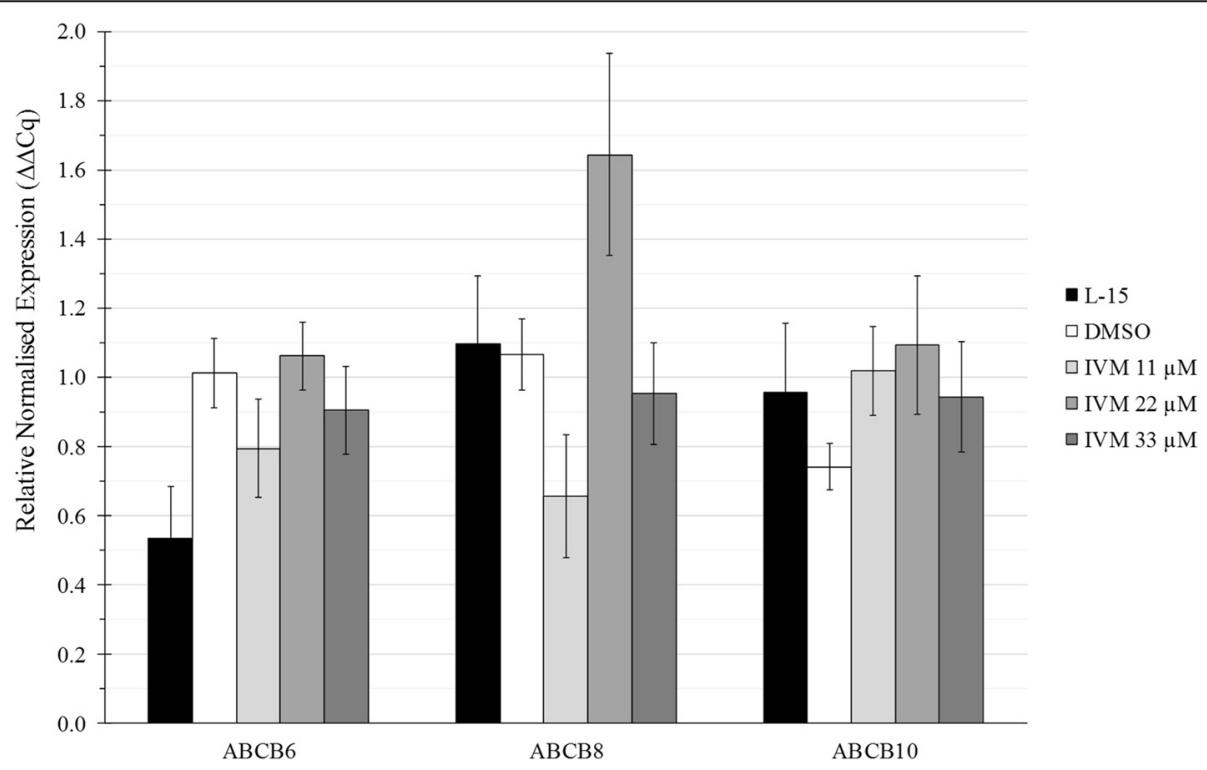

Fig. 4 Expression of ABCB6, $A B C B 8$ and $A B C B 10$ genes in IRE/CTVM19 cells untreated (L-15), treated with 0.1\% DMSO alone (DMSO) or treated with different concentrations of ivermectin (IVM) in $0.1 \%$ DMSO. Results were expressed as Relative Normalised Expression ( $\Delta \Delta \mathrm{Ct}$ ) vs expression of the housekeeping gene ( $\beta$-Actin) and were presented as the mean \pm S.E.M. of three experiments performed with four replicates each 
establishment of a lethal concentration $50\left(\mathrm{LC}_{50}\right)$ and of a resistant tick cell sub-line. In that study, up-regulation of several $\mathrm{ABC}$ genes (ABCB10, $\mathrm{ABCC} 1, \mathrm{ABCB} 7$, $A B C C 2)$ was observed in the ivermectin-resistant cell sub-line BME26-IVM.

Interestingly, the I. ricinus cell line used in the present study was able to tolerate a much higher concentration of ivermectin, $30 \mu \mathrm{g} / \mathrm{ml}(33 \mu \mathrm{M})$, than the unselected BME26 cell line that did not survive after exposure to a concentration of ivermectin of $12.5 \mu \mathrm{g} / \mathrm{ml}$ or the resistant sub-line BME26-IVM for which the $\mathrm{LC}_{50}$ was calculated as $15.1 \mu \mathrm{g} / \mathrm{ml}$ [7]. Differences between the biology of the two tick species from which the cell lines were derived (I. ricinus and R. microplus), between the phenotypic composition of the cell lines themselves and/ or in the culture conditions used (such as medium composition and incubation temperature) may explain the differences in the outcome of treatment and should be taken into account when refining the in vitro model of $I$. ricinus. Finally, it would be of interest to develop this in vitro model with cell lines from other economically important tick species and to evaluate the effect of different acaricides that have been reported to be losing their efficacy in the field [17].

\section{Competing interests}

The authors declare that they have no competing interests.

\section{Authors' contributions}

Experiments were conceived and designed by GG, CM and LK. Experiments were performed by CM and AV. Primers were designed by SE and DP. The data were analysed by LK and DO. LBS contributed reagents and materials. The manuscript was written by LK and GG and critically revised by LBS. All authors read and approved the final manuscript.

\section{Acknowledgements}

The present study was funded by PRIN project number \#2010PJJ4W3_004. The tick cell line IRE/CTVM19 was provided by the Tick Cell Biobank at The Pirbright Institute. The funders had no role in study design, data collection and analysis, decision to publish, or preparation of the manuscript.

\section{Author details}

${ }^{1}$ Department of Veterinary Sciences, University of Parma, 43126 Parma, Italy. ${ }^{2}$ The Pirbright Institute, Ash Road, Pirbright, Surrey GU24 ONF, Pirbright, UK. 'Department of Environmental Biology, University of Rome 'La Sapienza', Rome, Italy. ${ }^{4}$ Department of Veterinary Medicine, University of Bari, 70010 Bari, Italy. ${ }^{5}$ Department of Veterinary Science and Public Health, University of Milan, Milan, Italy. ${ }^{6}$ National Veterinary Institute, SVA, SE-751 89 Uppsala, Sweden.

Received: 8 January 2016 Accepted: 5 April 2016

Published online: 18 April 2016

\section{References}

1. Dantas-Torres F, Chomel BB, Otranto D. Ticks and tick-borne diseases: a One Health perspective. Trends Parasitol. 2012;28(10):437-46.

2. Dantas-Torres F, Otranto D. Best practices for preventing vector-borne diseases in dogs and humans. Trends Parasitol. 2015;32(1):43-55.

3. Otranto D, Wall R. New strategies for the control of arthropod vectors of disease in dogs and cats. Med Vet Entomol. 2008;22(4):291-302.

4. Krishna R, Mayer LD. Multidrug resistance (MDR) in cancer. Mechanisms, reversal using modulators of MDR and the role of MDR modulators in influencing the pharmacokinetics of anticancer drugs. Eur J Pharm Sci. 2000; 11(4):265-83.
5. Lara FA, Pohl PC, Gandara AC, Ferreira Jda S, Nascimento-Silva MC, Bechara GH, Sorgine MH, Almeida IC, Vaz Ida Jr S, Oliveira PL. ATP binding cassette transporter mediates both heme and pesticide detoxification in tick midgut cells. PLoS One. 2015;10(8):e0134779.

6. Pohl PC, Klafke GM, Carvalho DD, Martins JR, Daffre S, da Silva Vaz Jr I, Masuda A. ABC transporter efflux pumps: a defense mechanism against ivermectin in Rhipicephalus (Boophilus) microplus. Int J Parasitol. 2011; 41(13-14):1323-33.

7. Pohl PC, Klafke GM, Junior JR, Martins JR, da Silva Vaz Jr I, Masuda A. ABC transporters as a multidrug detoxification mechanism in Rhipicephalus (Boophilus) microplus. Parasitol Res. 2012;111(6):2345-51.

8. Pohl PC, Carvalho DD, Daffre S, Vaz Ida Jr S, Masuda A. In vitro establishment of ivermectin-resistant Rhipicephalus microplus cell line and the contribution of $A B C$ transporters on the resistance mechanism. Vet Parasitol. 2014;204(3-4):316-22.

9. Kurtti TJ, Munderloh UG, Ahlstrand GG, Johnson RC. Borrelia burgdorferi in tick cell culture: growth and cellular adherence. J Med Entomol. 1988;25(4):256-61.

10. Cafarchia C, latta R, Immediato D, Puttilli MR, Otranto D. Azole susceptibility of Malassezia pachydermatis and Malassezia furfur and tentative epidemiological cut-off values. Med Mycol. 2015;53(7):743-8.

11. Cossio-Bayugar R, Wagner GG, Holman PJ. In vitro generation of organophosphate resistant Boophilus microplus (Acari: Ixodidae) cell lines. J Med Entomol. 2002;39(2):278-84.

12. Taylor SM, Kenny J. An ivermectin sustained release bolus in cattle: its effects on the tick Ixodes ricinus. Med Vet Entomol. 1990;4(2):147-50.

13. Bell-Sakyi L, Zweygarth E, Blouin EF, Gould EA, Jongejan F. Tick cell lines: tools for tick and tick-borne disease research. Trends Parasitol. 2007;23(9): 450-7.

14. Lawson D, Arensburger P, Atkinson P, Besansky NJ, Bruggner RV, Butler R, Campbell KS, Christophides GK, Christley S, Dialynas E, et al. VectorBase: a data resource for invertebrate vector genomics. Nucleic Acids Res. 2009; 37(Database issue):D583-587.

15. Calabrese EJ. P-glycoprotein efflux transporter activity often displays biphasic dose-response relationships. Crit Rev Toxicol. 2008;38(5):473-87.

16. Ballent M, Lifschitz A, Virkel G, Sallovitz J, Mate L, Lanusse C. In vivo and ex vivo assessment of the interaction between ivermectin and danofloxacin in sheep. Vet J. 2012;192(3):422-7.

17. Eiden AL, Kaufman PE, Allan SA, Oi F. Establishing the discriminating concentration for permethrin and fipronil resistance in Rhipicephalus sanguineus (Latreille) (Acari: Ixodidae), the brown dog tick. Pest Manag Sci. 2015;32(1):43-55.

Submit your next manuscript to BioMed Central and we will help you at every step:

- We accept pre-submission inquiries

- Our selector tool helps you to find the most relevant journal

- We provide round the clock customer support

- Convenient online submission

- Thorough peer review

- Inclusion in PubMed and all major indexing services

- Maximum visibility for your research

Submit your manuscript at www.biomedcentral.com/submit 